\title{
Nocardia transvalensis keratitis: an emerging pathology among travelers returning from Asia
}

\author{
Elodie Trichet $^{1 \dagger}$, Stéphan Cohen-Bacrie ${ }^{2 \dagger}$, John Conrath ${ }^{1}$, Michel Drancourt ${ }^{2}$ and Louis Hoffart ${ }^{1 * \dagger}$
}

\begin{abstract}
Background: The incidence rate of Nocardia keratitis is increasing, with new species identified thanks to molecular methods. We herein report a case of Nocardia transvalensis keratitis, illustrating this emerging pathology among travellers returning from Asia.

Case presentation: A 23-year-old man presented with a 10-week history of ocular pain, redness, and blurred vision in his right eye following a projectile foreign body impacting the cornea while motor biking in Thailand. At presentation, a central epithelial defect with a central whitish stromal infiltrate associated with pinhead satellite infiltrates was observed. Identification with 165 rRNA PCR sequencing and microbiological culture of corneal scraping and revealed $N$. transvalensis as the causative organism. Treatment was initiated with intensive topical amikacin, oral ketoconazole and oral doxycycline. After a four-week treatment period, the corneal infiltrate decreased so that only a faint subepithelial opacity remained.

Conclusion: Nocardia organisms should be suspected as the causative agent of any case of keratitis in travelers returning from Asia. With appropriate therapy, Nocardia keratitis resolves, resulting in good visual outcome.
\end{abstract}

Keywords: Nocardia keratitis, amikacin, infectious keratitis

\section{Background}

Nocardia spp. keratitis is an aggressive ocular infection, typically following a corneal trauma. The diagnosis is often delayed, which can lead to a corneal scar [1]. While the most commonly identified agents have been Nocardia asteroides and Nocardia brasiliensis in the pre-molecular area [2], new species are now identified thanks to molecular methods and later two species are now rarely identified as clinical isolation. Herein, we report one case of Nocardia transvalensis keratitis, illustrating this emerging pathology among travelers returning from Asia.

\section{Case presentation}

A 23-year-old man presented with redness, pain and decreased visual acuity in his right eye following an injury caused by dust while driving a motorcycle in Thailand. Despite topical treatment with prednisolone and neomycin prescribed by a local ophthalmologist, the ocular

\footnotetext{
* Correspondence: louis.hoffart@orange.fr

† Contributed equally

'Service d'ophtalmologie, Hôpital de la Timone, Assistance Publique-

Hôpitaux de Marseille, Marseille, France

Full list of author information is available at the end of the article
}

condition did not improve after four weeks. Ten weeks later, the patient was referred to our ophthalmology department for further management of a persistent corneal ulcer. Upon initial examination, visual acuity was limited to "counting fingers" in the right eye and was 20/ 20 in the left eye. Slit-lamp examination of the right eye showed a well-defined, dense, whitish infiltrate in the central cornea with an epithelial defect of the same size (Figure 1A). Discrete patches of keratitis with pinhead satellite stromal infiltrates in the margin were also observed, but there was no anterior chamber reaction. Multiple scrapings of the ulcer bed and margins were obtained after topical anesthesia. $N$. transvalensis was cultivated by inoculating 5\%-sheep blood agar with the corneal scraping. The culture was incubated at $37^{\circ} \mathrm{C}$ in a $5 \% \mathrm{CO}_{2}$ atmosphere. The definite identification was based on partial sequencing of the 16S rRNA gene (over a length of 1.439 nucleotides), which showed a 99.79\% sequence similarity with the $N$. transvalensis stricto sensu reference sequence (GenBank accession number GQ217496.1) and a lower 98.96\% relatedness to Nocardia blacklockiae sequence (GenBank accession number GQ376162.1) and 98.55\% to Nocardia wallacei sequence 

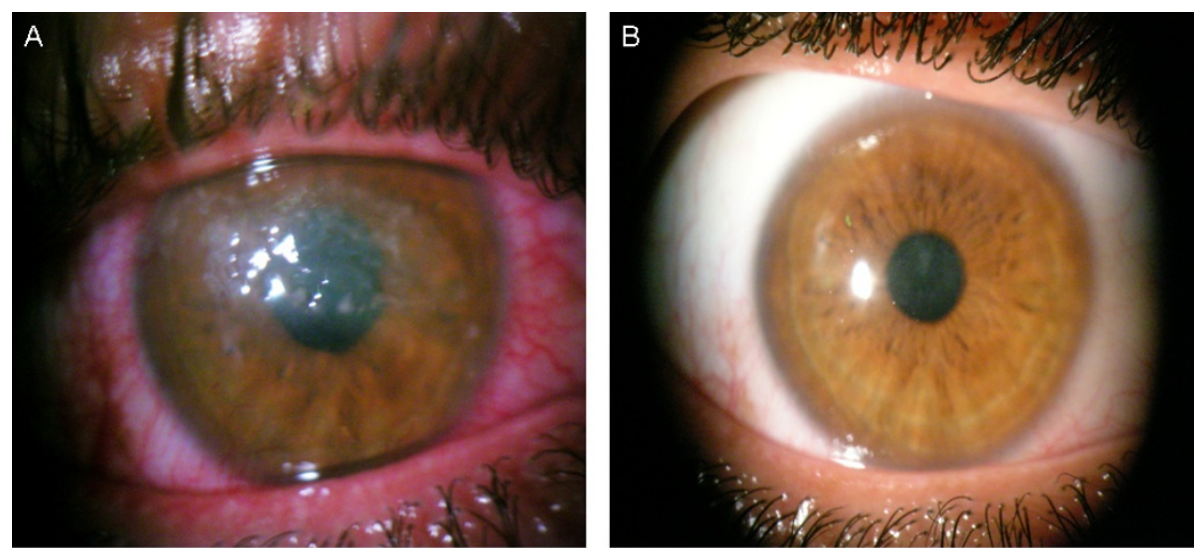

Figure 1 Nocardia transvalensis keratitis in a traveler returning from Thailand. (A) Initial clinical examination showed a whitish infiltrate in the central cornea; (B) Final aspect after 4 weeks of topical amikacin.

(GenBank accession number GQ853074.1). Additional microbiological analyses, including fungal culture and the molecular detection of amoebas and herpes simplex virus (based on the $18 \mathrm{~S}$ rDNA and DNA polymerase genes respectively), were negative. The patient was given topical amikacin $(50 \mathrm{mg} / \mathrm{ml})$ to be applied at hourly intervals in conjunction with oral ketoconazole (200 $\mathrm{mg}$ a day) and oral doxycycline (100 mg a day). After a four-week treatment period, the corneal infiltrate decreased so that only a faint subepithelial opacity remained (Figure 1B). Topical corticosteroids were then administered, and the patient recovered a visual acuity of $20 / 80$ three months after the beginning of the treatment. There was no evidence of recurrence during the one-year follow-up period.

In the case reported herein, temporal evidence links the infection and the airborne dust that the patient suddenly felt in his eye while motorbiking in Thailand. Moreover, the patient was not a contact-lens wearer, and he did not have any history of ocular problems. We thus concluded that the patient acquired the infection in Thailand. In this patient, $N$. transvalensis infection was firmly documented by culture and subsequent sequence-based identification. This second reported case of $N$. transvalensis ocular infection [3] indicates that $N$. transvalensis must be added to the list of Nocardia species associated with infectious keratitis [2,4]. Of a total of 73 reported cases of Nocardia spp. keratitis over the last five years, 67 (92\%) have been clearly acquired in individuals with direct links to Asia [2,3,5-16]. Whereas Nocardia spp. keratitis is a well-described clinical entity in Asia [1], it is seldom diagnosed in countries outside Asia. A recent visit to Asia therefore provides a clue for clinical diagnosis while waiting for PCR-based confirmation. Laboratory techniques have to be used to analyze every case of infectious keratitis because simple microscopic examination may mistakenly identify the case as fungal keratitis when the histopathology reveals acutebranching septate hyphae similar to those found in fungi. The most frequently noted predisposing factor for Nocardia keratitis is trauma, with surgery being the second most common factor. A few cases of Nocardia keratitis have also been reported in contact lens wearers, after refractive surgery and after implantation of intracorneal ring segments $[1,17]$.

Topical amikacin is commonly recommended to treat Nocardia keratitis [1] based on its in vitro antibacterial activity against Nocardia organisms [18], its demonstrated corneal penetration and its safety profile [19]. Several authors previously reported that the species $N$. transvalensis in fact comprises of an heterogeneous spectrum of organisms including both amikacin-susceptible and amikacin-resistant organisms, a hallmark of the $N$. transvalensis complex also incorporating the two newly described reported N. blacklockiae and N. wallacei [20]. In the patient herein reported, intensive tropical application resulted in complete resolution of the infection. One previously published case of $N$. transvalensis keratitis showed a decreased sensitivity to amikacin [3]. In fact, amikacin susceptibility and resistance have been determined on the basis of amikacin concentration achievable in serum during systemic Nocardia infections; as for Nocardia keratitis, amikacin is used as a topical antibiotic, achieving local concentrations far higher than those achievable during parenteral administration. While amikacin susceptibility profile could be used for the identification of Nocardia isolates, it is not useful for the topical treatment of Nocardia keratitis.

\section{Conclusions}

The rate of travel of Europeans to tropical regions in Asia for vacation or business has increased dramatically; more than 8 million travelers flew back from Asia to France in 
2009. Nocardia organisms should be suspected as the causative agent of any case of keratitis in travelers returning from Asia, especially those travelers who experienced a soil-borne corneal trauma and those who are contact lens wearers. Molecular tools may help in making a rapid diagnosis.

\section{Consent}

Written informed consent was obtained from the patient for publication of this report.

\section{Author details}

'Service d'ophtalmologie, Hôpital de la Timone, Assistance PubliqueHôpitaux de Marseille, Marseille, France. ${ }^{2}$ Pôle des Maladies Infectieuses, Assistance Publique-Hôpitaux de Marseille; Unité de Recherche sur les Maladies Infectieuses et Tropicales Emergentes, UMR CNRS 6236, IRD 3R 198, Université de la Méditerranée, IFR 48, Faculté de Médecine, Marseille, France.

\section{Authors' contributions}

TE wrote the case report; CBS did the laboratory work and wrote the manuscript; CJ took care of the patient; DM interpreted the data and wrote the manuscript; HL took care of the patient and wrote the manuscript. All authors read and approved the final version of the manuscript.

\section{Competing interests}

The authors declare that they have no competing interests.

Received: 28 January 2011 Accepted: 31 October 2011

Published: 31 October 2011

\section{References}

1. Lalitha P: Nocardia keratitis. Curr Opin Ophthalmol 2009, 20:318-23.

2. Sridhar MS, Sharma S, Reddy MK, Mruthyunjay P, Rao GN:

Clinicomicrobiological review of Nocardia keratitis. Cornea 1998, 17:17-22.

3. Pandya VB, Petsoglou C: Nocardia transvalensis resistant to amikacin: an unusual cause of microbial keratitis. Cornea 2008, 27:1082-5.

4. Reddy AK, Garg P, Kaur I: Spectrum and clinicomicrobiological profile of Nocardia keratitis caused by rare species of Nocardia identified by $16 \mathrm{~S}$ rRNA gene sequencing. Eye (Lond) 2010, 24:1259-62.

5. Hau SC, Dart JK, Vesaluoma M, Parmar DN, Claerhout I, Bibi K, Larkin DF: Diagnostic accuracy of microbial keratitis with in vivo scanning laser confocal microscopy. Br J Ophthalmol 2010, 94:982-7.

6. Garg P, Sharma S, Vemuganti GK, Ramamurthy B: A cluster of Nocardia keratitis after LASIK. J Refract Surg 2007, 23:309-12.

7. Rahimi F, Aghsaie Fard M, Soltani Mogaddam R: A case of amniotic membrane transplantation in non-healing Nocardia asteroides keratitis. J Ocul Biol Dis Infor 2009, 2:37-9.

8. Tsui I, Uslan DZ, Hubschman JP, Deng SX: Nocardia farcinica Infection of a Baerveldt implant and endophthalmitis in a patient with a Boston type I keratoprosthesis. J Glaucoma 2010, 19:339-40.

9. Javadi MA, Kanavi MR, Zarei S, Mirbabaei F, Jamali H, Shoja M, Mahdavi M, Naghshgar N, Yazdani S, Faramarzi A: Outbreak of Nocardia keratitis after photorefractive keratectomy: clinical, microbiological, histopathological, and confocal scan study. J Cataract Refract Surg 2009, 35:393-8.

10. Ramakrishnan R, Bharathi MJ, Shivkumar C, Mittal S, Meenakshi R, Khadeer MA, Avasthi A: Microbiological profile of culture-proven cases of exogenous and endogenous endophthalmitis: a 10-year retrospective study. Eye (Lond) 2009, 23:945-56.

11. Srinivasan M, Mascarenhas J, Prashanth CN: Distinguishing infective versus noninfective keratitis. Indian J Ophthalmol 2008, 56:203-7.

12. Mizota A, Haki K, Shiina C, Tanaka M, Nakazawa T, Yazawa K, Mikami Y: The first case of keratitis caused by Nocardia exalbida. Int Ophthalmol 2007, 27:333-6.

13. Matuska S, Rama P, Cavallero A, Paganoni G, Spinelli A, Brancato R: Nocardia keratitis: a case report. Eur J Ophthalmol 2006, 16:164-7.

14. Jain V, Dua N, Sridhar MS, Sharma S: Nocardia keratitis in a corneal graft. Eye (Lond) 2006, 20:385-6.
15. Hoffman PM, Poon A, Snibson GR: Nocardia keratitis in a contact lens wearer. Arch Ophthalmol 2005, 123:1759.

16. Patel NR, Reidy JJ, Gonzalez-Fernandez F: Nocardia keratitis after laser in situ keratomileusis: clinicopathologic correlation. J Cataract Refract Surg 2005, 31:2012-5.

17. Hofling-Lima AL, Branco BC, Romano AC, Campos MQ, Moreira H, Miranda D, Kwitko S, de Freitas D, Casanova FH, Sartori M, Schor P Souza LB: Corneal infections after implantation of intracorneal ring segments. Cornea 2004, 23:547-9.

18. Munoz J, Muñoz J, Mirelis B, Aragón LM, Gutiérrez N, Sánchez F, Español M, Esparcia O, Gurguí M, Domingo P, Coll P: Clinical and microbiological features of nocardiosis 1997-2003. J Med Microbio/ 2007, 56:545-50.

19. Lin CP, Boehnke M: Effect of fortified antibiotic solutions on corneal epithelial wound healing. Cornea 2000, 19:204-6.

20. Conville PS, Brown JM, Steigerwalt AG, Brown-Elliott BA, Witebsky FG: Nocardia wallacei sp. nov. and Nocardia blacklockiae sp. nov., human pathogens and members of the "Nocardia transvalensis Complex". J Clin Microbiol 2008, 46:1178-84.

\section{Pre-publication history}

The pre-publication history for this paper can be accessed here: http://www.biomedcentral.com/1471-2334/11/296/prepub

doi:10.1186/1471-2334-11-296

Cite this article as: Trichet et al:: Nocardia transvalensis keratitis: an emerging pathology among travelers returning from Asia. BMC Infectious Diseases 2011 11:296.

\section{Submit your next manuscript to BioMed Central and take full advantage of:}

- Convenient online submission

- Thorough peer review

- No space constraints or color figure charges

- Immediate publication on acceptance

- Inclusion in PubMed, CAS, Scopus and Google Scholar

- Research which is freely available for redistribution

Submit your manuscript at www.biomedcentral.com/submit
C) Biomed Central 